\title{
The Threshold of Anaerobic Biodegradation and Decolorization of Acid
}

\section{Dyes}

\author{
Li'an Ding ${ }^{1, a}$, Fang $\mathrm{Li}^{2, \mathrm{~b}}$, and Qing Tian ${ }^{1, \mathrm{c}}$ \\ ${ }^{1}$ College of environmental Science and Engineering, Donghua University, Shanghai 201620, China \\ a270428441@qq.com, 'lifang@dhu.edu.cn, ${ }^{\mathrm{T}}$ tq2004@dhu.edu.cn
}

Keywords: anaerobic, biodegradation, decolorization, acid dye

Abstract. Acid dyes were more difficult to be removed by chemical coagulation method due to their solubility. The threshold of anaerobic of acid dyes as model dyes was investigated in this paper by the analysis of the degradation products were detected by GC-MS. High COD removal and low decolorization of the acid sye was obtained during the batch experiment. According to GC-MS results, the possible degradation pathway of the dye was proposed that the organic compounds remained in the supernatant were likely composed of soluble microbial products and the aromatic amines which was related to threshold of decolorization of the acid dye.

\section{Introduction}

The textile industry is the third largest consumer of water in the world-behind at paper and oil industries, using enormous amounts of water for bleaching, sizing, desizing, mercerizing and dyeing. An estimated $17 \%$ to $20 \%$ of industrial water pollution comes from textile dyeing and an estimated 8,000 synthetic chemicals are used throughout the world to turn raw materials into textiles, many of which will be released into freshwater sources [1]. Textile wastewater is a mixture of many different compounds consisting of fiber, lint, dyes, acids, chemicals and non-biodegradable compounds from aromatic and heterocyclic compounds, oil and grease, hydrocarbons, surfactants, anionic compounds [2]. Color removal is a pertinent problem for the all textile wastewaters due to dyes usually have a synthetic origin and complex aromatic structures which make them more stable and more difficult to biodegrade [3].

Azo dyes, which are aromatic compounds with one or more $-\mathrm{N}=\mathrm{N}-$ groups, are the most common synthetic dyestuffs released to the environment via textile industries [4]. Anionic dyes for polyamide and protein substrates are known as acid dyes. Acid dyes derive their name because they are typically applied to the substrates from a medium containing acid. Comparing with other dyes, the acid dyes were more difficult to be removed by chemical coagulation method due to their solubility. Even at low concentrations, water soluble dyes are able to cause waste waters being highly colored [5]. Biodegradation of textile effluent is still considered as an attractive solution due to its low-cost, environmentally friendliness, and publicly acceptability [6].

In this paper, we aim at exploring the threshold of anaerobic of acid dyes, chosing as acid dyes as model dyes because of their typical structure. The biodegradation pathway was investigated with GC-MS analysis and evolution of the end products coming from the substrate mineralization. It can obtain a general picture of the overall process of the decolorization of acid dyes.

\section{Materials and methods}

Synthetic dye influent. The component of synthetic wastewater over mineral and trace elements contained with $1 \mathrm{~L}$ SBR feed followed: $480 \mu \mathrm{g} / \mathrm{L} \mathrm{CuCl}_{2} \bullet 2 \mathrm{H}_{2} \mathrm{O}, 680 \mu \mathrm{g} / \mathrm{L} \mathrm{Cr}\left(\mathrm{NO}_{3}\right) \bullet 9 \mathrm{H}_{2} \mathrm{O}, 100 \mu \mathrm{g} / \mathrm{L}$ 
$\mathrm{MnSO}_{4} \bullet \mathrm{H}_{2} \mathrm{O}, 300 \mu \mathrm{g} / \mathrm{L} \quad \mathrm{NiSO}_{4} \bullet 6 \mathrm{H}_{2} \mathrm{O}, \quad 50 \mu \mathrm{g} / \mathrm{L} \quad \mathrm{CoCl} \bullet 6 \mathrm{H} 2 \mathrm{O}, \quad 180 \mu \mathrm{g} / \mathrm{L} \quad \mathrm{ZnCl}_{2}, \quad 20 \mu \mathrm{g} / \mathrm{L}_{2} \quad \mathrm{~K}_{2} \mathrm{MoO}_{4}$, $5.8 \mathrm{mg} / \mathrm{L} \mathrm{FeSO} 4 \cdot 7 \mathrm{H}_{2} \mathrm{O}, 6 \mathrm{mg} / \mathrm{L} \mathrm{MgSO} 4 \cdot 7 \mathrm{H}_{2} \mathrm{O}$. Glucose, urea, and phosphorus sources provided by $\mathrm{KH}_{2} \mathrm{PO}_{4}$ (contributed to $214.5 \mathrm{mg} / \mathrm{L}$ ) would supply carbon, nitrogen sources and energy, which was designed to the ratio of 200:5:1(COD: N: P). Meanwhile, sodium bicarbonate served as inorganic carbon source was adjusted to $\mathrm{pH}$. The acid dyes, Lanaset red G.GR, used in the pilot experiment were provided by Huntsman Chemical Trading Co. Limited (Shanghai, China).

Sludge Acclimatization. The sludge used in the experiment was acquired from Songjiang wastewater Treatment Plant. The sludge was domesticated for $60 \mathrm{~d}$ in a reaction tank of $20 \mathrm{~L}$. The daily influent chemical oxygen demand COD concentration was controlled at $2000 \mathrm{mg} / \mathrm{L}$. The operation procedure of the reactor included two main steps: agitation for 23 hours and precipitation for $1 \mathrm{~h}$ a day with the inlet and outlet of $10 \mathrm{~L}$.

Reactor and batch experiments. The test was carried out in an $0.25 \mathrm{~m} \times 0.27 \mathrm{~m} \times 0.35 \mathrm{~m}$ anaerobic reactor with the valid volume of $20 \mathrm{~L}$. The reactor was equipped with a stirrer and the reaction temperature was controlled at $35^{\circ} \mathrm{C}$ by means of a water bath and a heating tube refluxing device.

GC-MS. The degradation products were detected by GC-MS. The extraction process of samples followed: centrifugation $(6000 \mathrm{r} / \mathrm{min}), 500 \mathrm{~mL}$ supernatant centrifuged placing in a $1000 \mathrm{~mL}$ separatory funnel, extraction 3 times by chromatographic pure $\mathrm{CH}_{2} \mathrm{Cl}_{2}$ used in the acidic and alkaline conditions, and the extracted liquid collected in the same container.The samples were separated by a rotary evaporator, evaporated to $5 \mathrm{~mL}$, and extracted with $2 \mathrm{~mL}$ of nitrogen blowoff. The concentrated sample was then analyzed by GC-MS.

\section{Results and Discussion}

COD removal. As shown in Fig. 1(a), high COD removal was obtained during the batch experiment, increasing from $54.8 \%$ at $24 \mathrm{~h}$ to $89.5 \%$ at $120 \mathrm{~h}$. In fact, COD removal reached the highest values during the acclimation period. The high COD removal during the acclimation period could be due to the operating conditions applied before the addition of the azo dye. High COD removal was due to the readily biodegradability of glucose which contributed $95 \%$ of the total COD value. At the end of the batch experiment, the organic compounds remained in the supernatant were likely composed of soluble microbial products and the aromatic amines that were produced by the azo dye cleavage. Therefore, the formed aromatic amines resulted refractory to anaerobic digestion as already reported in the literature.

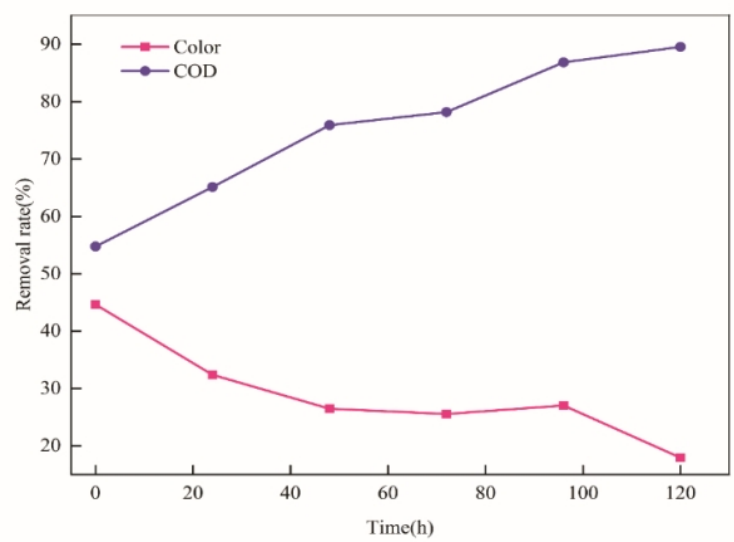

(a)

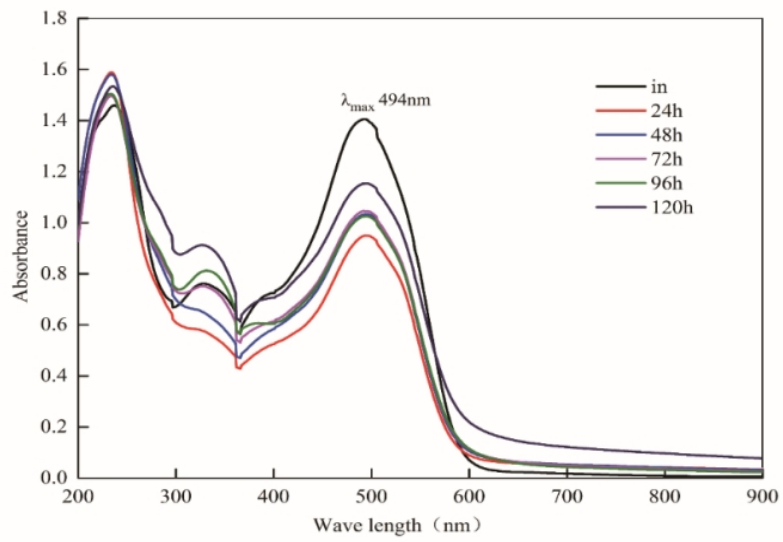

(b)

Fig. 1 COD removal UV-vis profile of the supernatant during the biodegradation of acid dyes 
Color removal. The color removal had an opposite trend with respect to COD removal as seen from Fig. 1(a), increasing continuously. UV-vis profile represented that the maximum absorption wavelength for of the Lanaset red G.GR was $494 \mathrm{~nm}, 320 \mathrm{~nm}$, and 254nm due to the main chromophore could be azo-bond. During the biodegradation process, the maximum absorption wavelength did not change while the absorbance value was significantly reduced. Therefore, it was indicated that the azo bond was broken partially. Moreover, the absorbance value increases with the retain time of the acid dyes. The absorbance at $320 \mathrm{~nm}$ was even higher $120 \mathrm{~h}$ than that of supernatant at $48 \mathrm{~h}$ to, inferring that a new auxiliary chromophore was probably generated in anaerobic biodegradation process. Meanwhile, the peak at the approximate $250 \mathrm{~nm}$ was also higher than that of influent after 24 hours, where there generally existed benzene ring, unsaturated hydrocarbons and other substances, acquiring a conjecture that these matter produced in the biodegradation process lead to the change of the peak.

GC-MS analysis. Mass spectra data and structure of identified compound after GC-MS analysis of dye degradation was shown in Table 1.

Table .1 Data of dye degradation by GC-MS analysis method

\begin{tabular}{rlcc}
\hline No. & \multicolumn{1}{c}{ Intermediate product } & Elutiontime (min) & $\mathrm{m} / \mathrm{z}$ \\
\hline 1 & 3,4-Dimethyl-1-phenyl-3-pyrazolin-5-one & 22.865 & 188.1 \\
2 & 3-nitroaniline & 22.528 & 138.043 \\
3 & aniline & 10.173 & 98.04 \\
4 & benzoic acid & 14.109 & 122.037 \\
5 & octanoic acid & 14.22 & 144.115 \\
6 & N-phenylacetohydrazide & 20.363 & 126.11 \\
7 & 3-amimo-2-hydroxy-5-nitrobenzenesulfonic acid & 27.265 & 245.043 \\
8 & 3-amimo-5-nitrobenzenesulfonic acid & 24.581 & 228.043 \\
9 & 3-amimo-4-nitrophenol & 17.764 & 164.043 \\
\hline
\end{tabular}

Those data presented that 3-nitroaniline, aniline, benzoic acid, octanoic acid and some alkanes were detected in 24 hours. Thus, it was presumed that the azo bonds of the dyes were mostly broken. Phenyl-3-pyrazolin-5-one, N-phenylacetohydrazide, 3-nitroaniline, aniline, benzoic acid and octanoic acid in 48 hours and 72 hours by means of GC-MS showed that the azo bond was broken but not completely decomposed. The carbon-oxygen unsaturated conjugated bonds of 3 , 4-Dimethyl-1-phenyl-3-pyrazolin-5-one and $\mathrm{N}$-phenylacetohydrazidew were characterized as chromophoric groups, verifying the reason mightily was related to the decline of color removal. 3,4-Dimethyl-1-phenyl-3-pyrazolin-5-one, phenylacetohydrazide, 3-amimo-2-hydroxy-5-nitrobenzenesulfonic acid, 3-amimo-5-nitrobenzenesulfonic acid,3-amimo-4-nitrobenzenesulfonic acid, 3-amimo-4-nitrophenol, 3-nitroaniline, aniline, benzoic acid, and octanoic acid among those production were detected from $72 \mathrm{~h}$ to $120 \mathrm{~h}$. The sulfonic acid groups and hydroxyl groups in nitrophenol were all co-coloring groups, which also can explain the possibility of UV-vies change at near $350 \mathrm{~nm}$ and $250 \mathrm{~nm}$. Therefore, according to those results, it was probably obtained about the course of dye degradation, as illustrated in Fig. 2. 

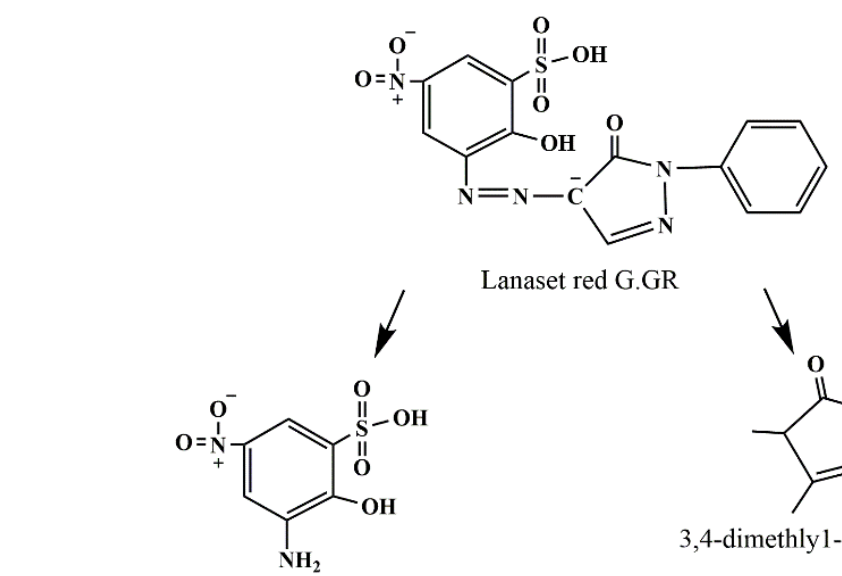

Lanaset red G.GR

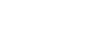

3-amino-2-hydroxy-5-nitrobenzenesulfonic acid

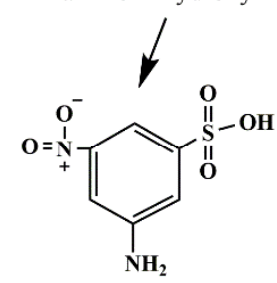

3-amino-5nitrobenzenesulfonic acid d

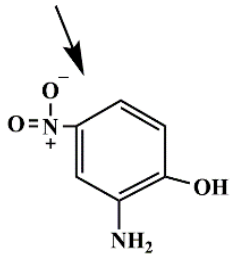

2-amino-4-nitrophenol

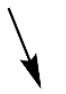<smiles>[NH3+]c1cccc([N+](=O)[O-])c1</smiles>

3-nitroaniline

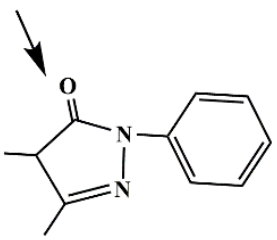

3,4-dimethly1-1-pheny1-3pyrazolin-5-one<smiles>CC(=O)N(N)c1ccccc1</smiles>

$\mathrm{N}$-phenylacetohydrazide

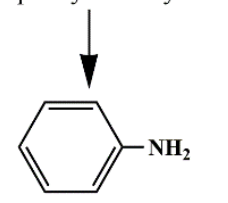

aniline

$\downarrow$

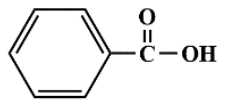

Benzoic acid

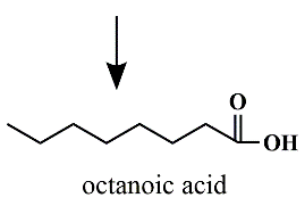

Fig.2 the biodegradation pathway of the acid dye, Lanaset red G.GR

\section{Conclusions}

The results demonstrated that the batch experiment under anaerobic conditions can achieve a high COD removal and low decolourisation of wastewater containing acid dyes. It was observed that COD and aromatic amines were mainly generated under the anaerobic condition and remained in the supernatant even at long retaining time, i.e. $120 \mathrm{~h}$. High efficient decolourisation of Lanaset acid dyes was hardly achieved through solo biodegradation. The threshold of anaerobic biodegradation and decolorization of acid dyes was due to the refractory the aromatic amines that were produced by the azo dye cleavage.

\section{Acknowledgements}

This work is supported by the National Natural Science Foundation of China (51478099), national key research and development plan (2016YFC0400501), Natural Science Foundation of Shanghai (16ZR1402000) . 


\section{References}

[1] Angelis-Dimakis, A., Alexandratou, A. and Balzarini, A., (2016), Value chain upgrading in a textile dyeing industry, Journal of Cleaner Production 138(2), 237-247.

[2] Ozturk, E., Koseoglu, H. and Karaboyaci, et al., (2016), Sustainable textile production: cleaner production assessment/eco-efficiency analysis study in a textile mill, Journal of Cleaner Production 138(2), 248-263.

[3] Stolz, A., (2000), Basic and applied aspects in the microbial degradation of azo dyes, Appl. Microbiol. Biotechnol 56(1-2), 69-80

[4] Popli, S., Patel, U.D., (2015), Destruction of azo dyes by anaerobic-aerobic sequential biological treatment: a review, International Journal of Environmental Science and Technology 12(1), 405-420.

[5] Moosvi, S., Kher, X. and Madamwar, D., (2007), Isolation, characterization and decolorization of textile dyes by a mixed bacterial consortium JW-2, Dyes Pigment 74(3), 723-729.

[6] Aravin, P., Selvaraj, H and Ferro S., et al., (2016), Destruction of azo dyes by anaerobic-aerobic sequential biological treatment: a review An integrated (electro- and bio-oxidation) approach for remediation of industrial wastewater containing azo-dyes: Understanding the degradation mechanism and toxicity assessment, Journal of Hazardous Materials 318, 203-215. 